\title{
NUMERICAL MODELLING OF KINEMATICS AND DYNAMICS OF SPILLING AND PLUNGING BREAKERS IN SHALLOW WATERS
}

Mayilvahanan Alagan Chella, University of Notre Dame, malaganc@nd.edu Hans Bihs, Norwegian University of Science and Technology, hans.bihs@ntnu.no

\section{INTRODUCTION}

Wave breaking is a complex two-phase flow process that strongly influences the air-water interaction. A number of physical processes are involved in the exchange of mass, momentum and energy between air and water interaction during the wave breaking process. In shallow waters, waves undergo different transformation processes such as shoaling, refraction, diffraction and breaking due to their non-linear interaction with the seabed. Thus, the associated hydrodynamics are rather complicated to understand when compared to wave breaking in deep water (Lin, 2008). In the present numerical study, a twophase flow CFD model REEF3D (Bihs et al. 2016) is used to model and investigate the hydrodynamics of spilling and plunging breakers over a slope. An accurate modeling of the wave breaking process is still highly demanding due to the strong non-linear air-water interaction and turbulent production at the free surface. The numerical wave tank is based on the incompressible Reynolds Averaged Navier-Stokes (RANS) equations together with the level set method for free surface and the $k-\omega$ model for turbulence (Alagan Chella et al. 2015). The model uses the 5th-order Weighted Essentially NonOscillatory (WENO) scheme for the convective discretization and the 3rd-order TVD Runge Kutta Scheme for the time discretization. A staggered grid method is employed in the model in order to achieve a stronger coupling between the pressure and velocity. The model is fully parallelized with the domain decomposition method and MPI (Message passing interface).

\section{MAIN RESUTLS}

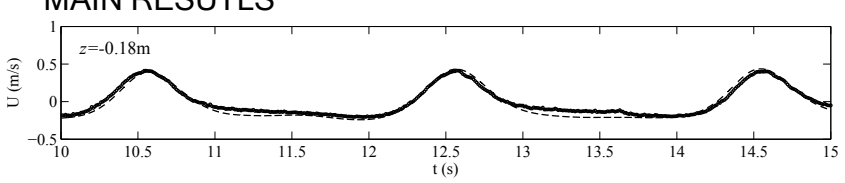

(a) $x=5.945 \mathrm{~m}$ (before breaking)

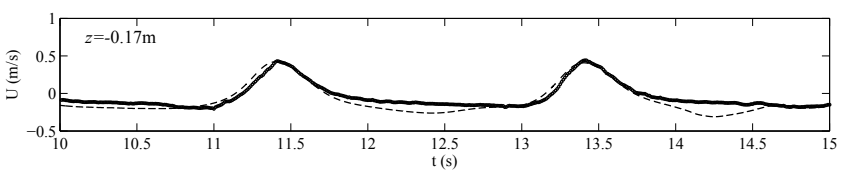

(b) $x=6.665 \mathrm{~m}$ (during breaking)

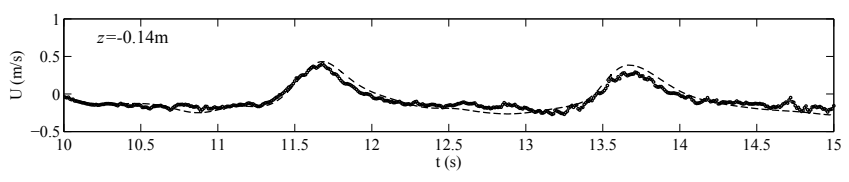

(c) $x=7.275 \mathrm{~m}$ (after breaking)

Figure 1 Comparison of numerical and experimental results for horizontal particle velocity $(u)$ for spilling breakers.

The numerical model for simulating wave breaking over a slope is validated against experimental data by Ting and Kirby (1994) for both spilling breaker and plunging breakers. Figures 1 to 4 present the comparison of numerical results and experimental data for horizontal (Figures 1 and 3 ) and vertical (Figures 2 and 4 ) velocity components. Comparisons of numerical results and experimental data by Ting and Kirby (1994) show good agreement for both velocity components.

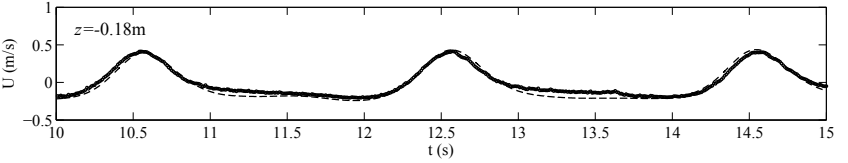

(a) $x=5.945 \mathrm{~m}$ (before breaking)

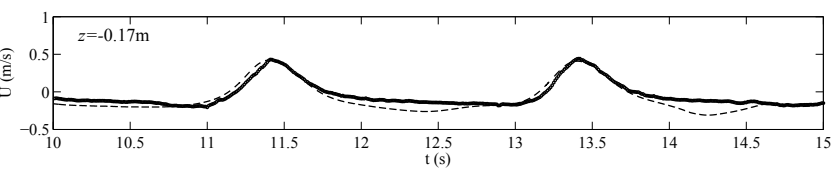

(b) $x=6.665 \mathrm{~m}$ (during breaking)

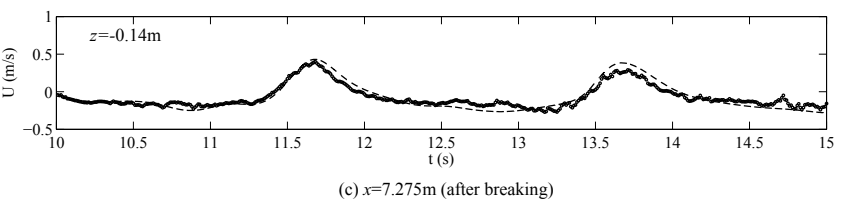

Figure 2 Comparison of numerical and experimental results for horizontal particle velocity $(u)$ for plunging breakers.
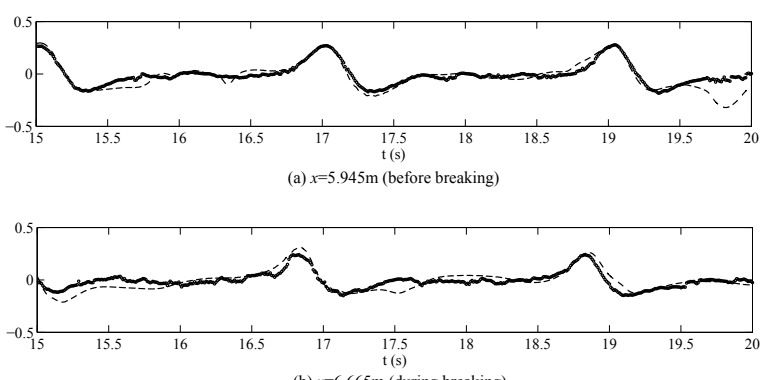

(b) $x=6.665 \mathrm{~m}$ (during breaking)

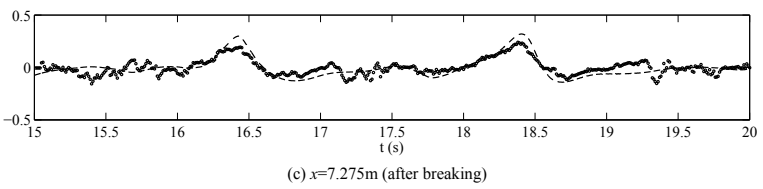

Figure 3 Comparison of numerical and experimental results for vertical particle velocity $(w)$ for spilling breakers.
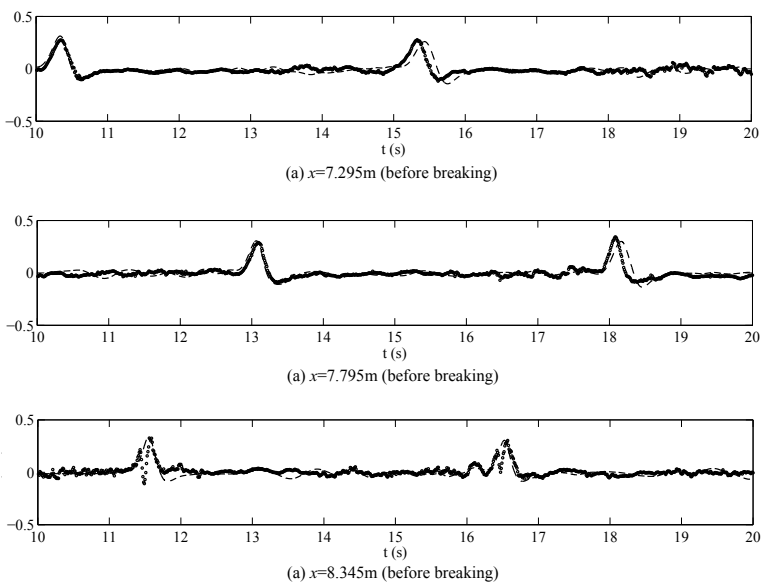

Figure 4 Comparison of numerical and experimental results for vertical particle velocity $(w)$ for spilling breakers. 
Further, the asymmetric properties of the wave shape evolution during the breaking process are accessed with steepness and asymmetry parameters proposed by (Kjeldsen and Myrhaug, 1978). The parameters are the crest front steepness $(\varepsilon)$, the crest rear steepness $(\delta)$, the horizontal asymmetry factor $(\mu)$ and the vertical asymmetry factor $(\lambda)$. Figures 5 and 6 show the geometric properties of the wave profile during breaking at different locations over a slope up to the breaking point for spilling and plunging breakers. Then, the study also examines the undertow and turbulence intensity of each breaker after breaking in the surf zone.
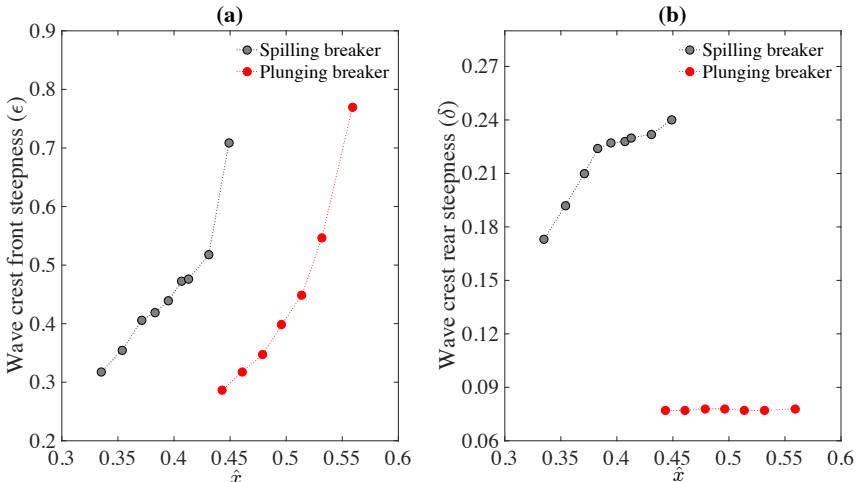

Figure 5 Comparison between spilling and plunging breakers for geometric properties ( $\varepsilon$ and $\delta$ ).
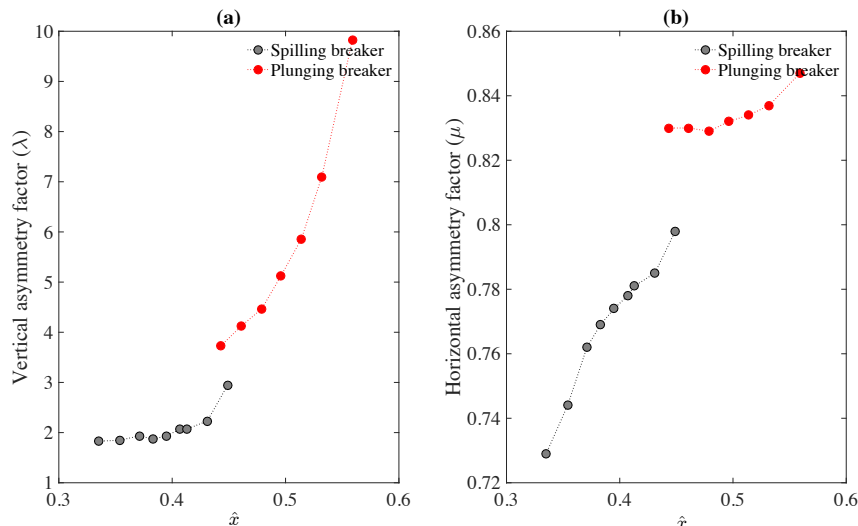

Figure 6 Comparison between spilling and plunging breakers for geometric properties ( $\lambda$ and $\mu$ ).

Figures 7 and 8 present the free surface deformations during the breaking process for spilling and plunging breakers, respectively. Moreover, the hydrodynamics of the wave transformation during the initial breaking process are investigated in order to gain more insights into the physical processes. It is found that the wave undergoes more deformation for the plunging breaker than for the spilling breaker as it breaks at a shallower water depth with a larger breaker height. Therefore, the wave height to water depth ratio $\mathrm{H} / \mathrm{d}$ is larger for the plunging breaker than for the spilling breaker. Most of the flow features associated with the breaking process such as the development of the overturning wave crest and airpocket, the splash-up and the breaking induced secondary wave crest are well represented in the numerical simulation.

\section{REFERENCES}

Bihs, H., Kamath, A., Alagan Chella, M., Aggarwal, A., Arntsen, Ø.A., 2016. A new level set numerical wave tank with improved density interpolation for complex wave hydrodynamics. Computers and Fluids 140, 191-208.

Alagan Chella, M., Bihs, H., Myrhaug, D. and Muskulus, M. (2016), Hydrodynamic characteristics and geometric properties of plunging and spilling breakers over impermeable slopes, Ocean Modelling, 103, 53-72.
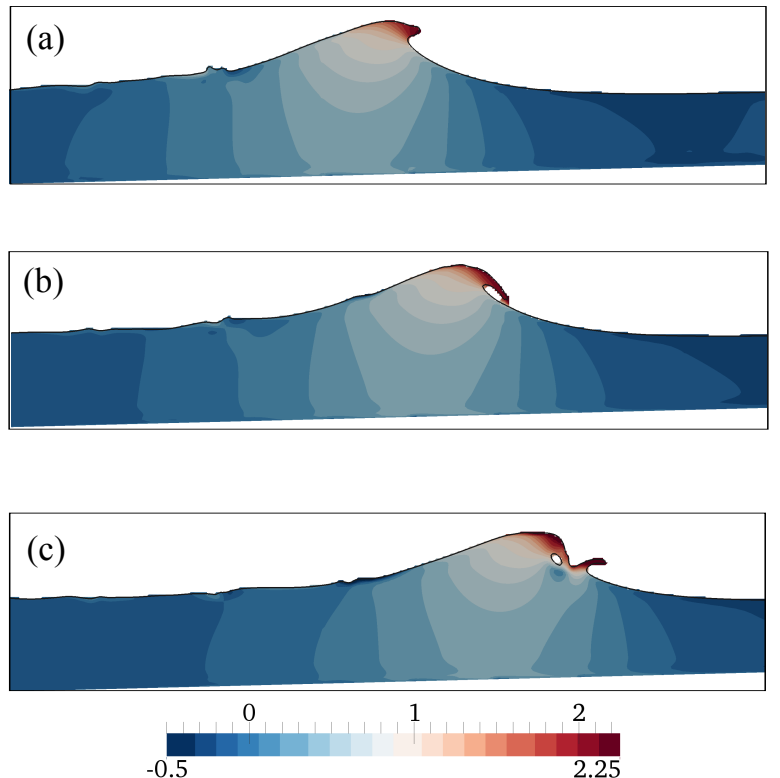

Figure 7 Free surface deformation with $u(\mathrm{~m} / \mathrm{s})$ for spilling breakers.
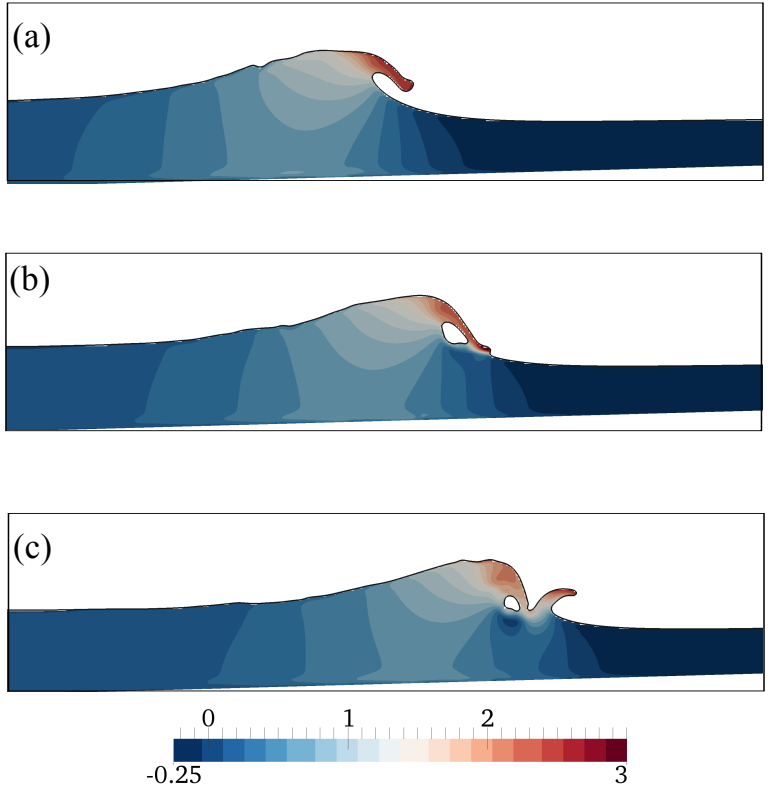

Figure 8 Free surface deformation with $u(\mathrm{~m} / \mathrm{s})$ for plunging breakers.

Lin, P. (2008), Numerical modeling of water waves, CRC Press.

Ting, F.C., Kirby, J.T., 1994. Observation of undertow and turbulence in a laboratory surf zone. Coastal Engineering, $24,51-80$

Kjeldsen, S.P., Myrhaug, D., 1978. Kinematics and Dynamics of Breaking Waves. Technical Report. River and Harbour Laboratory $(\mathrm{NHL})$, The Norwegian Institute of Technology. 